\title{
GAMBARAN TEKAN INTRAOKULAR PADA PEMAIN MUSIK BAMBU
}

\author{
${ }^{1}$ Rampi C.N \\ ${ }^{2}$ Engka J.N.A \\ ${ }^{2}$ Pangemanan D.H.C
}

\author{
${ }^{1}$ Kandidat skripsi Fakultas Kedokteran Universitas Sam Ratulangi Manado \\ ${ }^{2}$ Bagian Fisologi Fakultas Kedokteran Universitas Sam Ratulangi Manado \\ Email: chintya.rampi@yahoo.com
}

\begin{abstract}
Intraocular pressure (IOP) is an important measure because corelated with glaucoma that can lead to blindness if not prevented early. Factors affecting the intraocular pressure include gender, age, nationality, race, physiological differences such as high blood pressure and cardiovascular disease. Music is a product of human culture. One kind of music is a bamboo wind instrument that originated from Minahasa, comprised of flute, saxophone, Corno, trombone, tuba, bass, and trumpet. This study was aimed to reveal the IOP of a bamboo wind instrument players from Pinapalangkou village - South Minahasa. This was an observational cross sectional study. The research sample amounted to 31 people who have met the inclusion criteria, ie 15-83 years old, physically and mentally healthy while doing research, had been playing music for more than 1 year, willing to be sampled and signed informed consent. Measurement of IOP using a schiotz tonometer. Based on the results there were 31 male player, and at night inspection was found that there were 3 people (9.7\%) had an increase of IOP and 28 people (90.3\%) had normal IOP. There are 3 subjects from 31 studied subjects had an elevated intraocular pressure while 28 studied subjects had normal IOP.
\end{abstract}

Keywords: intraocular pressure, Bamboo Music Players

\begin{abstract}
Abstrak: Tekanan intraokular merupakan ukuran yang penting karena berhubungan penyakit glaukoma yang dapat menyebabkan kebutaan jika tidak dicegah sejak dini. Faktor yang mempengaruhi tekanan intraokular adalah jenis kelamin, usia, bangsa, ras, perbedaaan fisiologis seperti darah tinggi dan kardiovaskular. Musik adalah produk kebudayaan manusia. Salah satunya musik tiup bambu yang berasal dari Minahasa. Terdiri dari seruling, saxophone, corno, trombone, tuba, bass, dan trompet. Penelitian ini bertujuan untuk mengetahui gambaran tekanan intraokular pada pemain musik tiup bambu di desa Pinapalangkou - Minahasa Selatan. Penelitian ini bersifat observasional, dengan rancangan cross sectional study. Sampel penelitian berjumlah 31 orang yang telah memenuhi kriteria inklusi yaitu berumur 15-83 tahun, sehat jasmani dan rohani saat dilakukan penelitian, lebih dari 1 tahun memainkan musik, bersedia dijadikan sampel penelitian dan menandatangani informed consent. Pengukuran tekanan intraokular mengunakan alat tonometer schiotz. Berdasarkan hasil penelitian terdapat 31 pemain pria, pemeriksaan pada malam hari didapatkan bahwa ada 3 orang $(9,7 \%)$ mengalami peningkatan tekanan intraokular dan 28 orang $(90,3 \%)$ memiliki tekanan intraokular dalam batas normal. Terdapat 3 subjek dari 31 subjek memiliki peningkatan tekanan intraokular sedangkan 28 subjek memiliki tekanan intraokular dalam batas normal.
\end{abstract}

Kata kunci: Tekanan Intraokular,Pemain Musik Tiup Bambu 
Indonesia dewasa ini menghadapi masalahmasalah kesehatan utama angka kelahiran yang masih tinggi, kurangnya kesadaran serta pengertian dari masyarakat terhadap usaha-usaha kesehatan, keadaan gizi yang masih jelek, keadaan hygiene dan sanitasi yang jauh dari memuaskan serta penyakit menular yang masih merajalela. Umumnya menyadari bahwa kesehatan adalah salah satu syarat dalam mencapai pembangunan dibidang sosial ekonomi yang optimal. Kesadaraan itu juga termasuk tentang kesehatan mata dan kebutaan. ${ }^{1}$

Diperkirakan lebih dari 3 juta kebutaan di dunia disebabkan oleh glaukoma sudut terbuka primer dan lebih dari 100 juta penduduk di dunia cenderung terjadi peningkatan tekanan intraokular dimana sekitar 2,4 juta dari populasi tersebut berkembang menjadi glaukoma sudut terbuka primer setiap tahun. Glaukoma menjadi penyebab kedua kebutaan setelah katarak. $^{2,3}$

Tekanan intraokular merupakan ukuran yang penting diambil untuk kesehatan mata, karena penelitian membuktikan bahwa kaitan antara tekanan intraokular dengan penyakit glaukoma menjadi salah satu faktor yang dapat menyebabkan kebutaan jika tidak dicegah sejak dini. Walaupun sekarang terdapat kaitan antara saraf dengan penyakit glaukoma, peningkatan tekanan intraokular masih menjadi perhatian serius karena ini merupakan salah satu yang boleh menyebabkan glaukoma berkembang jika tekanan intraokular tidak dikontrol. Faktor yang mempengaruhi tekanan intraokular ini termasuk jenis kelamin, usia, perbedaaan fisiologis seperti darah tinggi dan kardiovaskular. ${ }^{4}$

Glaukoma adalah suatu keadaan di mana tekanan intraokular mata seseorang meningkat tinggi ( $>20 \mathrm{mmHg}$ ) dan kadangkadang mencapai 60-70 mmHg sehingga mengakibatkan kerusakan saraf optik dan mengakibatkan gangguan pada sebagian atau seluruh lapangan pandang atau buta. 5,6

Musik adalah produk kebudayaan manusia. Keterkaitan musik dan manusia selalu menjadi fokus karena kebudayaan adalah konseptual (cognitive) dan perilaku (behavior) masyarakat. Musik adalah bahasa universal, tidak ada etnik di dunia yang tidak bermusik. Alat musik tiup menghasilkan bunyi dengan cara di tiup. Contoh alat musik tiup bambu dan trompet. $^{7,8}$

Penulis Schuman JS, et al. menunjukan bahwa pemain musik tiup nada tinggi dan rendah mengalami peningkatan tekanan intraokular yang sementara. Peningkatan tekanan intraokular lebih besar pada pemain musik tiup nada tinggi dari pada pemain nada rendah. Penulis Aydin $P$, Oram O, Akman A, Dursun D menunjukan bahwa pemain musik tiup instrumen yang signifikan dapat meningkatkan tekanan intraokular pada orang yang sehat. Penulis Schmidtmann G, Jahnke S, Seidel J.E, Sickenberger $\mathrm{W}$ menunjukan bahwa pemain musik pada instrument kuningan (brass instruments) dan suling (woodwind instruments) menyebabkan peningkatan tekanan intraokular dan tekanan darah tergantung pada frekuensi nada yang dimainkan. ${ }^{9-11}$

Berdasarkan penelitian dan landasan teori di atas, penulis tertarik melakukan penelitian gambaran tekanan intraokular pada pemain musik tiup bambu.

\section{METODE PENELITIAN}

Penelitian yang akan dilakukan menggunakan design cross sectional study. Penelitian dilakukan di Desa Pinapalangkow, Minahasa Selatan pada bulan Desember 2012. Teknik pengambilan sampel pada penelitian ini yaitu menggunakan tekhnik random sampling. Populasi pada penelitian ini yaitu sekelompok pemain musik tiup bambu di desa Pinapalangkow Minahasa Selatan. Dan subjek pada penelitian ini yaitu bagian dari populasi pemain musik tiup di desa Pinapalangkow Minahasa Selatan, yang memenuhi kriteria inklusi: berusia 15-83 tahun, sehat jasmani dan rohani saat akan di teliti, sudah bermain $\geq 1$ tahun, bersedia untuk dijadikan subjek penelitian. Variabel bebas ialah pemain musik tiup bambu. Dan variabel terikat ialah tekanan intraokular. 
Instrumen penelitian yang digunakan antara lain: Tonometer Schiotz, Obat tetes anestesi lokal (pantokain 0,5\%), Beban, Alkohol, Kapas dan kasah steril, Alat tulis menulis, Obat anti infeksi. Definisi operasional tekanan intraokular adalah tekanan cairan di dalam bola mata yang diciptakan oleh produksi terus-menerus dan drainase cairan ke ruang anterior. Nilai normal tekanan intraokular $\leq 20 \mathrm{mmHg}$. Pengukuran menggunakan alat tonometer schiotz, dan dilakukan pada malam hari. Definisi operasional pemain musik tiup bambu adalah sekelompok orang yang berusia 15-83 tahun yang bermain musik tiup bambu baik secara kelompok sanggar yang ada di Desa PinapalangkowMinahasa Selatan. Prosedur penelitian yakni; Persiapan, berupa permohonan izin penelitian kepada pihak penanggungjawab sanggar musik tiup bambu, penandatanganan informed consent oleh responden yang telah memenuhi kriteria inklusi, dilakukan wawancara dengan menggunakan kuisioner. Tahap pelaksanaannya responden dikumpulkan kemudian dilakukan pengukuran tekanan intarokular, responden kemudian dijelaskan mengenai tujuan dan cara kerja tonometri schiotz. Kemudian dilakukan pemeriksaan tekanan intraokular setelah itu dilakukan pemeriksaan tekanan darah. Data yang diperoleh kemudian dikumpulkan dan diolah untuk mendapatkan karakteristik dan gambaran tekanan intraokular pada pemain musik bia yang kemudian disajikan dalam bentuk tabel distribusi frekuensi.

\section{HASIL PENELITIAN}

Telah dilakukan penelitian mengenai Tekanan Intraokular pada Pemain Musik Tiup Bambu. Subyek penelitian adalah Pemain musik Bambu di desa Pinapalangkou - Minahasa Selatan berusia 15 - 83 tahun. Jumlah subyek yang diteliti adalah 31 subyek dan jenis kelamin seluruhnya adalah laki-laki.

Tabel 1. Distribusi frekuensi subyek berdasarkan umur

\begin{tabular}{|c|c|c|c|c|c|c|c|c|c|c|c|c|c|c|c|}
\hline \multirow{3}{*}{$\begin{array}{l}\text { Umur } \\
\text { (Tahun) }\end{array}$} & \multirow{3}{*}{$\mathbf{n}$} & \multicolumn{13}{|c|}{$\mathbf{n}$} & \multirow{3}{*}{$\%$} \\
\hline & & \multicolumn{6}{|c|}{ TIOD } & \multicolumn{7}{|c|}{ TIOS } & \\
\hline & & 8,5 & 10,2 & 12,2 & 14,6 & 17,3 & 20,6 & 8,5 & 10,2 & 12,2 & 14,6 & 15,9 & 17,3 & 20,6 & \\
\hline $11-20$ & 5 & 2 & & & & 2 & 1 & & & 1 & & & 3 & 1 & 16,1 \\
\hline $21-30$ & 3 & & & 1 & 2 & & & & & 2 & & 1 & & & 9,7 \\
\hline $31-40$ & 4 & & & 2 & & 2 & & & 1 & 1 & 1 & & & 1 & 12,9 \\
\hline $41-50$ & 7 & 1 & 2 & 1 & 2 & 1 & & 3 & & 1 & 2 & & 1 & & 22,5 \\
\hline $51-60$ & 5 & & & 1 & 2 & 2 & & & 1 & 1 & & 1 & 2 & & 16,1 \\
\hline $61-70$ & 2 & & & & 2 & & & & & & 1 & & 1 & & 6,5 \\
\hline $71-80$ & 2 & & & & 2 & & & & & 2 & & & & & 6,5 \\
\hline $80-90$ & 3 & & & 1 & 2 & & & & 1 & 1 & 1 & & & & 9,7 \\
\hline Total & 31 & & & & & & & & & & & & & & 100 \\
\hline
\end{tabular}

Tabel 1, menunjukkan umur subyek penelitian dengan distribusi terbanyak pada umur 41-50 tahun dengan jumlah 7 subjek $(22,5 \%)$ dan yang paling sedikit yaitu umur 61-70 tahun dan 71-80 tahun dengan jumlah 2 subjek (6,5\%).
Diikuti dengan distribusi terbanyak TIOS 17,3 mmHg dan 8,5 mmHg pada umur 1120 tahun dengan 5 subjek $(16,1 \%)$ dan 4150 tahun dengan 7 subjek ( 22,5\%). 
774 Jurnal e-Biomedik (eBM), Volume 1, Nomor 2, Juli 2013, hal. 771-778

Tabel 2. Distribusi subjek berdasarkan jenis musik

\begin{tabular}{|c|c|c|c|c|c|c|c|c|c|c|c|c|c|c|}
\hline \multirow{3}{*}{ Jenis Musik } & \multirow{3}{*}{$\mathrm{n}$} & \multicolumn{13}{|c|}{$\mathrm{n}$} \\
\hline & & \multicolumn{6}{|c|}{ TIOD } & \multicolumn{7}{|c|}{ TIOS } \\
\hline & & 8,5 & 10,2 & 12,2 & 14,6 & 17,3 & 20,6 & 8,5 & 10,2 & 12,2 & 14,6 & 15,9 & 17,3 & 20,6 \\
\hline Corno & 12 & 1 & & 4 & 5 & 2 & 1 & & 1 & 5 & 2 & & 3 & 1 \\
\hline Tuba & 3 & & & & 2 & 1 & & & & & 2 & & 1 & \\
\hline Suling & 4 & & & & 2 & 2 & & & 1 & & 1 & & 2 & \\
\hline Clarinet & 4 & & 1 & 1 & 2 & & & 1 & 1 & 1 & & 1 & & \\
\hline Saxophone & 2 & & & 1 & 1 & & & & 1 & & & & 1 & \\
\hline Bass & 3 & & & 1 & 2 & & & & 1 & 1 & & & 1 & \\
\hline Trombone & 3 & 1 & 1 & & 1 & & & 1 & & 1 & & 1 & & \\
\hline Total & 31 & & & & & & & & & & & & & \\
\hline
\end{tabular}

Tabel 2, menunjukkan alat musik yang dapat meningkatkan tekanan intraokular dengan distribusi terbanyak adalah alat musik corno sebanyak 12 subjek dan paling sedikit adalah trompet sebanyak 1 subjek. Diikuti tekanan intraokular subjek terbanyak pada alat musik corno sebanyak 5 subjek dengan TIOD $14,5 \mathrm{mmHg}$ dan TIOS 12,2 mmHg. Terdapat 3 subjek yang mengalami peningkatan dengan TIOD 20,6
mmHg sebanyak 1 subjek dan TIOS 20,6 mmHg sebanyak 2 subjek.

Tabel 3, menunjukkan sejak kapan mulai meniup musik bambu dengan distribusi terbanyak adalah sejak 1-10 tahun dengan 16 subjek dan yang paling sedikit adalah sejak 21-30 tahun dan 31-40 tahun dengan 3 subjek. Terjadi peningkatan TIOD dan TIOS 20,6 mmHg sejak bermain 1-10 tahun.

Tabel 3. Distribusi subjek berdasarkan sejak kapan meniup musik bambu

\begin{tabular}{|c|c|c|c|c|c|c|c|c|c|c|c|c|c|c|}
\hline \multirow{3}{*}{$\begin{array}{c}\text { Sejak } \\
\text { (Tahun) }\end{array}$} & \multirow{3}{*}{$\mathbf{n}$} & \multicolumn{13}{|c|}{ n } \\
\hline & & \multicolumn{6}{|c|}{ TIOD } & \multicolumn{7}{|c|}{ TIOS } \\
\hline & & 8,5 & 10,2 & 12,2 & $\begin{array}{c}14, \\
6 \\
\end{array}$ & $\begin{array}{c}17 \\
3\end{array}$ & $\begin{array}{c}20 \\
6\end{array}$ & $\begin{array}{l}8, \\
5\end{array}$ & $\begin{array}{c}10, \\
2\end{array}$ & $\begin{array}{c}12, \\
2\end{array}$ & $\begin{array}{c}14, \\
6 \\
\end{array}$ & $\begin{array}{c}15, \\
9\end{array}$ & $\begin{array}{c}17 \\
3\end{array}$ & $\begin{array}{c}20, \\
6 \\
\end{array}$ \\
\hline 110 & 17 & 1 & 2 & 3 & 7 & 3 & 1 & 2 & 2 & 4 & 2 & 1 & 4 & 2 \\
\hline 1120 & 8 & 1 & & 2 & 3 & 2 & & & & 4 & 1 & & 3 & \\
\hline $21-30$ & 3 & & & 1 & 2 & & & & 1 & 1 & 1 & & & \\
\hline $31-40$ & 3 & & & & 3 & & & & 1 & & 1 & & 1 & \\
\hline Total & & & & & & & & & & & & & & \\
\hline
\end{tabular}

Tabel 4. Distribusi frekuensi subyek berdasarkan frekuensi latihan

\begin{tabular}{|c|c|c|c|c|c|c|c|c|c|c|c|c|c|c|}
\hline \multirow{3}{*}{$\begin{array}{c}\text { Frekuensi } \\
\text { Latihan } \\
\text { /minggu }\end{array}$} & \multirow{3}{*}{$\mathbf{n}$} & \multicolumn{13}{|c|}{$\mathbf{n}$} \\
\hline & & \multicolumn{6}{|c|}{ TIOD } & \multicolumn{7}{|c|}{ TIOS } \\
\hline & & 8,5 & 10,2 & 12,2 & 14,6 & 17,3 & 20,6 & 8,5 & 10,2 & 12,2 & 14,6 & 15,9 & 17,3 & 20,6 \\
\hline 1-2 kali & 29 & 1 & 2 & 6 & 15 & 5 & & 2 & 4 & 7 & 5 & 2 & 7 & 2 \\
\hline 2-3 kali & 2 & 1 & & & & & 1 & & & 1 & & & 1 & \\
\hline Total & 31 & & & & & & & & & & & & & \\
\hline
\end{tabular}


Tabel 4, menunjukkan mengenai distribusi frekuensi responden berdasarkan subjek dan latihan. Dapat dilihat bahwa terdapat 31 orang yang melakukan latihan, dengan persentase $100 \%$ dari total keseluruhan. Untuk frekuensi latihan yang paling banyak yaitu 1-2 kali dalam seminggu yaitu 28 subjek, dan yang paling sedikit yaitu 2-3 kali dalam seminggu hanya terdapat 2 subjek. Pada frekuensi latihan 1-2 kali dalam seminggu terdapat 2 subjek mengalami peningkatan tekanan intraokular dengan TIOS 20,6 mmHg diikuti 1 subjek mengalami peningkatan tekanan intraokular dengan TIOD 20,6 mmHg sebanyak 1 subjek.

Tabel 5, menunjukkan mengenai distribusi berdasarkan TIOD dan TIOS dengan distribusi terbanyak TIOD 14,6
mmHg sebanyak 13 subjek dan TIOS 12,2 mmHg dan 17,3 mmHg sebanyak 8 subjek diikuti distribusi paling sedikit TIOD 20,6 mmHg sebanyak 1 orang dan TIOS 8,5 mmHg, 15,9 mmHg dan 20,6 mmHg sebanyak 2 orang. Distribusi terbanyak memiliki tekanan intraokular dalam batas normal sedangkan yang sedikit terdapat 1 subjek mengalami peningkatan TIOD.

Tabel 6, menunjukkan mengenai distribusi frekuensi nilai tekanan intraokular pada pemeriksaan tonometer schiotz. Pada pemeriksaan ini distribusi terbanyak adalah tekanan intraokular yang normal yaitu 28 subjek (90,3\%) dan yang sedikit adalah tekanan intraokular yang meningkat terdapat 3 subjek (9,7\%).

Tabel 5. Distribusi subjek berdasarkan TIOD dan TIOS

\begin{tabular}{cccc}
\hline TIOD $(\mathbf{m m H g})$ & $\mathbf{n}$ & TIOS $\mathbf{( m m H g )}$ & $\mathbf{n}$ \\
\hline 8,5 & 2 & 8,5 & 2 \\
10,2 & 2 & 10,2 & 4 \\
12,2 & 5 & 12,2 & 8 \\
14,6 & 13 & 14,6 & 5 \\
15,9 & - & 15,9 & 2 \\
17,3 & 4 & 17,3 & 8 \\
20,6 & 1 & 20,6 & 2 \\
\hline Total & 31 & & 31 \\
\hline
\end{tabular}

Tabel 6. Distribusi frekuensi subyek berdasarkan nilai tekanan intraokular

\begin{tabular}{ccc}
\hline Tekanan Intaokular & n & $\mathbf{\%}$ \\
\hline Normal (11-20 mmHg) & 28 & 90,3 \\
Meningkat ( >20 mmHg) & 3 & 9,7 \\
\hline Total & 31 & 100
\end{tabular}

\section{BAHASAN}

Jenis kelamin merupakan salah satu faktor yang mempengaruhi tekanan intraokular. Berdasarkan teori bahwa tidak banyak ditemui perbedaan tekanan intra-okular antara pria dan wanita. Umumnya wanita usia menopause mempunyai tekanan intraokular yang relatif lebih tinggi di bandingkan pria umur yang sama. Hal ini berhubungan dengan perbedaan karakteristik fisiologi wanita dan laki-laki. ${ }^{3,12}$ Pada penelitian ini terdapat 31 subjek dengan jenis kelamin laki-laki. 
Alat musik tiup terdiri dari alat musik instrumen suling (woodwind instruments) dan instrumen kuningan (brass instruments). Yang termasuk alat musik instrument suling (woodwind instruments) adalah suling, clarinet dan instrumen kuningan (brass instruments) adalah trompet, corno, trombone, tuba, saxophone. Berdasarkan Schuman JS menunjukan bahwa pemain musik tiup nada tinggi dan rendah mengalami peningkatan tekanan intraokular yang sementara. Peningkatan tekanan intraokular lebih besar pada pemain musik tiup nada tinggi dari pada pemain nada rendah. Penulis Aydin P, Oram O, Akman Dursun D, menunjukan bahwa pemain musik tiup instrumen yang signifikan dapat meningkatkan tekanan intraokular pada orang yang sehat. Penulis Schmidtmann G, Jahnke S, Seidel J.E, Sickenberger $\mathrm{W}$ menunjukan bahwa pemain musik pada instrument kuningan (brass instruments) dan suling (woodwind instruments) menyebabkan peningkatan tekanan intraokular dan tekanan darah tergantung pada frekuensi nada yang dimainkan, ${ }^{9-11}$ Pada penelitian ini menunjukkan bahwa alat musik dengan distribusi terbanyak adalah alat musik corno sebanyak 12 subjek dan paling sedikit adalah saxophone sebanyak 2 orang. Pada alat musik corno terdapat 3 subjek yang mengalami peningkatan dengan TIOD 20,6 mmHg 1 subjek dan TIOS 20,6 mmHg sebanyak 2 subjek. Tidak diketahui dengan pasti faktor-faktor yang mempengaruhi.

Tekanan intraokular biasanya akan peningkatan apabila seseorang sudah lama meniup alat musik tiup karena pemain musik tiup bambu dimainkan dengan cara ditup. Pada meniup terjadi pembuangan nafas paksa (manuver valsava). Jadi semakin lama seseorang memainkan musik tiup khususnya musik tiup bambu biasanya dapat meningkatkan tekanan intraokular yang sementara dan menetap, tapi perubahan nilai tekanan intraokular ini juga dapat meningkat dengan faktorfaktor yang mempengaruhi. Pada penelitian ini terdapat distribusi terbanyak adalah sejak 1-10 tahun dengan subjek 16 orang dan yang paling sedikit adalah sejak 21-30-dan 31-40 tahun dengan subjek 3 orang. Terjadi peningkatan TIOD dan TIOS 20,6 mmHg sejak bermain 1-10 tahun.

Berdasarkan penelitian Schmidtmann bahwa Latihan secara rutin dapat mengubah tekanan intraokular seseorang. ${ }^{11}$ Hasil distribusi latihan sebagian besar tidak menunjukkan adanya peningkatan tekanan intraokular karena subjek tidak melakukan latihan secara rutin, kebanyakan subjek melakukan latihan 1-2 kali dalam seminggu. Penelitian ini terdapat 31 subjek yang melakukan latihan, dengan persentase $100 \%$ dari total keseluruhan. Untuk frekuensi latihan yang paling banyak yaitu 1-2 kali dalam seminggu adalah 29 subjek, dan yang paling sedikit adalah 2-3 kali dalam seminggu sebanyak 3 subjek. Pada frekuensi latihan 1-2 kali dalam seminggu terdapat 2 subjek mengalami peningkatan tekanan intraokular dengan TIOS 20,6 mmHg dan terdapat 1 subjek dengan TIOD 20,6 mmHg.

Tekanan intraokular normal rata-rata antara 12-20 mmHg (21). Ada perbedaan nilai pemeriksaan pada mata kanan dan mata kiri. Pada penelitian ini terdapat peningkatan tekanan intraokular 0,6 mmHg sehingga menjadi 20,6 mmHg sebanyak 3 subjek. Distribusi terbanyak sebanyak 13 subjek dengan TIOD 14,6 mmHg dan sebanyak 8 subjek dengan TIOS 12,2 mmHg dan 17,3 mmHg orang diikuti distribusi paling sedikit TIOD 20,6 mmHg sebanyak 1 subjek dan TIOS 8,5 mmHg, 15,9 mmHg dan 20,6 mmHg sebanyak 2 subjek. Belum diketahui dengan pasti faktor-faktor terjadinya peningkatan pada pengukuran ini.

Secara keseluruhan penelitian ini tekanan intraokular yang normal terbanyak adalah orang yang berumur lanjut dengan tekanan darah dalam batas normal sedangkan peningkatan tekanan intraokular terjadi pada orang yang berumur 15 tahun sebanyak 2 orang dan 35 tahun 
sebanyak 1 orang dengan tekanan darah abnormal (>120/80mmHg). Hasil ini jika dibandingkan dengan teori tidak sesuai karena tekanan intraokular akan meningkat dengan bertambah umur, diusia muda mempunyai tekanan yang lebih rendah dibanding usia tua. Pada orang tua peningkatan tekanan intraokular ini mempunyai hubungan dengan tekanan darah yang meningkat, frekuensi nadi dan obesitas. ${ }^{3,12}$ Berdasarkan penelitian Schmidtmann bahwa sebagian besar hubungan tekanan intraokular dan tekanan darah tidak signifikan, tapi pada umumnya peningkatan tekanan darah biasa disertai dengan peningkatan tekanan intraokular. ${ }^{11}$ Pada pemeriksaan ini belum diketahui dengan pasti faktor-faktor yang mempengaruhi peningkatan tekanan intraokular.

Melalui observasi kuisioner terdapat 27 orang sehat dan 4 orang yang ada riwayat penyakit hipertensi dengan nilai tekanan intraokular dalam batas normal. Pada penelitian ini hanya diketahui riwayat hipertensi karena di desa tersebut tidak memiliki alat yang memadai untuk melakukan pemeriksaan lain. Hasil penelitian Schmidtmann menunjukkan bahwa sebagian besar hubungan antara tekanan intraokular dan tekanan darah tidak signifikan, tapi pada umumnya peningkatan tekanan darah biasa disertai dengan peningkatan tekanan intraokular. ${ }^{11}$

Berdasarkan penelitian ini terdapat 31 orang yang menjadi subjek penelitian dengan jenis kelamin seluruhnya adalah laki-laki. 3 orang mengalami peningkatan tekanan intraokular dan 28 orang yang memiliki tekanan intraokular yang normal. Hasil pemeriksaan ini belum signifikan karena pemeriksaan dilakukan pada malam hari. Pemeriksaan tekanan itntraokular baik dilakukan pada pagi hari apabila dibandingkan siang hari dan pada malam hari.

\section{SIMPULAN}

31 orang yang menjadi subjek penelitian, ada 3 orang $(9,7 \%)$ mengalami peningkatan tekanan intraokular dan 28 orang (90,3\%) memiliki tekanan intraokular dalam batas normal.

\section{DAFTAR PUSTAKA}

1. Mandang J.H.A. Penelitian perbandingan tentang glaukoma pada golongan orang minahasa yang diam urban dan rural area. Universitas Sam Ratulangi, Manado, 1977.

2. Harrison. Prinsip-prinsip ilmu penyakit dalam, ed. 13, Universitas Kedokteran UGM-ECG, Jakarta, 1977.

3. Zaldi. Perbedaan tekanan intraokular pria dan wanita emmetropia berusia 40 tahun atau lebih. Fakultas kedokteran Ilmu Penyakit Mata, Sumatera Utara, 2003.

4. Norhani M \& Norsuhana W.A. 'Sains Malaysia'. Tekanan intraokular dalam populasi klinik, 2010 ;39(2), h. 333-36.

5. Iiyas H. S. Glaukoma, ed. 3. Fakultas kedokteran indonesia, Jakarta 2007.

6. Corwin E.J. Buku saku patofisiologi, Ed. 3. Buku kedokteran (EGC), Jakarta, 1795.

7. Masduki. Menjadi broadcaster profesional. Pustaka Populer Lkis, Yogyakarta, 2004.

8. Tim Sains Quadra. Ilmu pengetahuan alam dasar kelas 4 Semester Dua, Yudhistira, Jakarta, 2007.

9. Aydin P, Oram O, Akman A, Dursun D. 'Glaucoma'. Effect of wind instrument playing on intraocular pressure, Departement Ophthalmology, Baskent University, School of Medicine, Ankara Turkey, 2000; 9(4) h. 322-4.

10. Schuman JS, et al. 'Ophthalmology'. Increased intraocular pressure and visual field defects in high resistance wind instrument players. University School of medicine, Boston Massachusetts 0211, USA. 2000; 107(1), h. 127-33

11. Schmidtmann G, Jahnke S, Seidel J.E, Sickenberger $\mathrm{W}$. Intraocular pressure fluctuations in professional brass and woodwind musicians during common playing conditions. Department of Visions Sciences, Glasgow Caledonian University. Greefes Arch Clin Expo Ophthalmology, 2011.

12. Sativa O. Tekanan intraokular pada penderita myopi ringan dan sedang. Fakultas Kedokteran Ilmu Penyakit mata, Sumatera Utara, 2003. 
13. Manuver valsava. Available at: http://id.wikipedia.org/wiki/Manuver_Val sava (Accessed: 25 juli 2012).

14. Susanto I. Pengenalan suara alat musik dengan metode jaringan saraf tiruan. Fakultas Teknik, Jurusan Teknik Elektro, Universitas Diponegoro, Semarang. 2011.

15. Media Indonesia. Musik bia masuk buku guiness world records. 2010. Diakses pada: 25 October 2012.

16. Banoe P. Kamus musik. Kanisius, Yogyakarta, 2003.

17. Woodwind instruments. 2010. Available at:gigglepotz.com/music/ppt/Woodwind\% 20instruments.ppt8

18. Renaldy Y. Perkembangan musikt tradisional indonesia. (Accessed: 25 oktober 2012).

19. Sejarah musik bambu. Available at: http://acsujabodetabek.wordpress.com (Accessed: 30 maret 2012).

20. Guyton \& Hall. Buku ajar fisiologi kedokteran, Ed. 11. Buku kedokteran (EGC). Jakarta, 2006. 